\title{
Identification of Novel Markers for the Diagnosis of Malignant Pleural Mesothelioma
}

\author{
Fabien Gueugnon, ${ }^{*}$ Sabrina Leclercq, ${ }^{*}$ \\ Christophe Blanquart, ${ }^{*}$ Christine Sagan, ${ }^{\dagger}$ \\ Laurent Cellerin, ${ }^{\neq}$Martine Padieu, ${ }^{*}$ \\ Christian Perigaud, ${ }^{\S}$ Arnaud Scherpereel," \\ and Marc Gregoire*
}

\begin{abstract}
From INSERM U892,* Centre de Recherche en Cancérologie Nantes-Angers, Nantes; the Service d'Anatomie Pathologique, the Service de Pneumologie, ${ }^{\ddagger}$ and the Service d'Oncologie Médicale Thoracique et Digestive, ${ }^{\S}$ Hôpital Laënnec, CHU de Nantes; and the Service de Pneumologie et Oncologie Thoracique, "CHRU de Lille, Faculté de Médecine Henri-Warembourg, Université de LilleII, INSERM U1019, CIIL, Lille, France
\end{abstract}

The diagnosis of malignant pleural mesothelioma is difficult, with the most common differential diagnoses being benign pleural diseases and metastatic adenocarcinomas (ADCA). To identify novel markers that would be able to improve diagnostic accuracy, we performed a genome-wide gene expression analysis on tumor cell lines established from pleural effusions (malignant pleural mesothelioma and lung ADCA). This analysis led to the identification of genes encoding novel and pertinent cellular and soluble markers, for which the expression was validated by real-time RT-PCR. Immunohistochemical staining of tumor biopsy specimens with anti-type III collagen antibodies showed positive labeling for mesothelioma cells but not for ADCA cells. Using enzyme-linked immunosorbent assay, we showed that the C-C motif chemokine 2 (CCL2) concentration was significantly higher in pleural effusions from patients with mesothelioma $(n=61)$ than in subjects with ADCA $(n=25)$ or with benign pleural effusions $(n=15)$ : median (interquartile range) $=2.99 \mathrm{ng} / \mathrm{ml}(1.76$ to 6.01$) \mathrm{vs} 0.99 \mathrm{ng} / \mathrm{ml}$ ( 0.51 to 1.83$)$ and $1.47 \mathrm{ng} / \mathrm{ml}(0.80$ to 1.56$)$, respectively, $P<0.0001$. Conversely, the galectin- 3 concentration was lower in mesothelioma: $11.50 \mathrm{ng} / \mathrm{ml}(6.73$ to 23.53$) \mathrm{vs}$ $24.74 \mathrm{ng} / \mathrm{ml}(20.42$ to 70.35$)$ and $17.64 \mathrm{ng} / \mathrm{ml}(14.81$ to 24.68), respectively, $P<0.0001$. The areas under the curve for CCL2 were 0.8030 and 0.7716 for the differentiation of mesothelioma from ADCA or benign pleural effusions, respectively. Similarly, the areas under the curve obtained for galectin-3 were 0.7980 and 0.6923 , respectively. In conclusion, type III col- lagen, CCL2, and galectin-3 are promising new diagnostic markers for mesothelioma. (Am J Pathol 2011, 178:1033-1042; DOI: 10.1016/j.ajpath.2010.12.014)

Malignant pleural mesothelioma (MPM) is a highly aggressive tumor with a poor prognosis. MPM is strongly associated with previous asbestos exposure, ${ }^{1}$ and its incidence is expected to increase during the next two decades in industrialized countries. ${ }^{2}$ Because MPM exhibits a broad range of cytomorphologic features and grows in a wide variety of histologic patterns, immunohistochemistry of pleural biopsy specimens, rather than cytologic examination of pleural effusions, has been considered the best approach for diagnosis. ${ }^{3,4}$ This technique, based on the staining of biopsy specimens using antibodies directed against a panel of validated markers frequently expressed in MPM (positive markers) or in carcinomas (negative markers), allows for accurate diagnosis in most cases. However, multiple biopsy specimens must be obtained to ascertain a firm and reliable histologic diagnosis, and for many patients, obtaining multiple specimens is difficult. Research has been conducted to identify soluble markers to help establish the early diagnosis of MPM in pleural effusions and in the blood of patients. Several interesting candidates, such as soluble mesothelin-related peptides (SMRPs), have been suggested. ${ }^{5-8}$ SMRP, which is mainly expressed by the mesothelioma epithelioid subtype, is currently the best soluble marker candidate; it displays a good specificity but lacks sensitivity. ${ }^{9}$ A combination of SMRP with an-

Supported by a postdoctoral fellowship from La Fondation pour la Recherche Médicale and La Région Pays de la Loire to F.G. and grants from INSERM, La Ligue Régionale contre le Cancer (Vendée, Morbihan, Maine et Loire, Sarthe, Deux Sèvres), La Fondation de l'Avenir, and the Nantes University Hospital (Hôtel Dieu)

S.L. and C.B. contributed equally to this work.

Accepted for publication December 7, 2010.

Supplemental material for this article can be found at http://ajp. amjpathol.org and at doi:10.1016/j.ajpath.2010.12.014.

Address reprint requests to Marc Gregoire, Ph.D., Institut de Recherche Thérapeutique de l'Université de Nantes, 8 quai Moncousu - BP 70721, 44007 Nantes cedex 1, France. E-mail: marc.gregoire@nantes.inserm.fr. 
Table 1. Characteristics of Recruited Patients

\begin{tabular}{lccc}
\hline \multicolumn{1}{c}{ Characteristic } & MPM $(n=61)$ & ADCA $(n=25)$ & BPE $(n=15)$ \\
\hline Age, year (mean \pm SD) & $67.8 \pm 10.2$ & $66.4 \pm 13.4$ & $70.1 \pm 12.6$ \\
Male sex, $\mathrm{n}(\%)$ & $51(83.6)$ & $7(28)$ & $13(86.6)$ \\
Confirmed asbestos exposure, $\mathrm{n}(\%)$ & $27(44.2)$ & & $4(26.6)$ \\
Histology & & & \\
Epithelioid & 49 & & \\
Sarcomatoid & 4 & & \\
Mixed type & 5 & $10(40)$ \\
Unspecified & 3 & $6(24)$ \\
Primary tumor, $\mathrm{n}(\%)$ & & $3(12)$ \\
Lung ADCA & & $2(8)$ \\
Breast ADCA & & $4(16)$ \\
Ovarian ADCA & & & \\
Digestive ADCA & & & \\
Unknown origin & & & \\
\hline
\end{tabular}

other marker or markers may result in a better classification and management of patients.

In recent years, gene expression profiling with largescale microarrays has been used in many cancers to identify pathways involved in malignant transformation and to find novel candidate diagnostic and prognostic markers. These studies have been conducted with the use of tumor specimens, ${ }^{10-15}$ but this approach requires samples with a high proportion of tumor cells. Furthermore, because biopsy specimens may contain several cell types, expression levels of genes specifically expressed by cancer cells may be hidden or minimized. Microarray results may be biased, which can lead to the identification of markers lacking specificity. To overcome the issue of tumor heterogeneity, some authors have used laser capture microdissection to isolate cell subpopulations. ${ }^{16}$ Although it is more specific than microarrays performed with the whole tumor tissue, this technique does not exclude contamination with stromal and immune cells, which generally are in close contact with cancer cells.

The aim of the present study was to perform a genomewide analysis using a collection of cancer cells isolated from pleural effusions. Our microarray data, confirmed by real-time RT-PCR, led to the identification of several novel genes preferentially expressed by MPM cells. Among the newly identified putative markers, we showed that type III collagen may be useful in immunohistochemistry. Furthermore, C-C motif chemokine 2 (CCL2) and galectin-3 levels were measured in an independent set of pleural fluids and proved helpful in differentiating MPM from other pleural diseases.

\section{Materials and Methods}

\section{Pleural Fluid Collection}

Pleural effusion samples from 101 patients suspected to have or with a recent diagnosis of MPM or metastatic adenocarcinoma (ADCA) were collected aseptically at the Laënnec Hospital (St-Herblain, France) between 1998 and 2010. Samples were centrifuged at $2500 \mathrm{rpm}$ in a Heraeus Multifuge for 20 minutes at $+4^{\circ} \mathrm{C}$, and supernatants were aliquoted and stored at $-80^{\circ} \mathrm{C}$. All patients gave informed consent and had not received any prior chemotherapy. Pathologic diagnosis relied on both fluid cytology and immunohistochemical analysis of pleural biopsies obtained by thoracoscopy. Final diagnosis, established by the anatomopathologic department (Laënnec Hospital, St-Herblain, France) and confirmed by the Pathology French Group for Assistance in the Diagnosis of Mesothelioma, divided the patients into three groups (Table 1): 61 patients with MPM, 25 patients with pleural metastasis of various carcinomas (ADCA group), and 15 patients with benign pleural effusions (BPEs).

\section{Cell Lines}

Mesothelioma and lung ADCA cell lines were established from pleural effusions collected by thoracocentesis of patients with cancer. Briefly, cell pellets obtained after centrifugation of pleural fluids were resuspended in sterile Roswell Park Memorial Institute-1640 medium (SigmaAldrich, Saint-Quentin Fallavier, France). Erythrocytes were removed by density gradient centrifugation in Ficollcontaining media lymphocyte separation medium 1077 (PAA Laboratories, Les Mureaux, France). Cells were washed twice in Roswell Park Memorial Institute-1640 medium and plated in six-well plates at a density of $2.10^{6}$ cells/well. Cells were cultured in Roswell Park Memorial Institute-1640 medium supplemented with $10 \%$ heat-inactivated fetal calf serum, $2 \mathrm{mmol} / \mathrm{L}$ L-glutamine, $100 \mathrm{IU} / \mathrm{ml}$ penicillin, and $0.1 \mathrm{mg} / \mathrm{ml}$ streptomycin (all reagents from Sigma-Aldrich). Two days after plating, nonadherent cells were removed by thorough washing. Tumor cells grew as monolayers and could be maintained in culture for up to 30 passages without any obvious change in morphology, phenotype, and behavior. Tumor cells were characterized for the expression of a panel of markers commonly used for the differential diagnosis of MPM (see Supplemental Figure S1 at $h$ ttp://ajp.amjpathol.org). The small-cell lung carcinoma (H69) and lung carcinoma (A549) cell lines were purchased from ATCC (LGC Promochem, Molsheim, France).

\section{Immunofluorescence}

Tumor cells were cultured on glass coverslips until 50\% to $60 \%$ confluence was achieved. Cells were fixed with 
4\% paraformaldehyde in PBS (15 minutes at room temperature). For intracellular staining, cells were permeabilized with $0.05 \%$ Triton X-100 (Merck, Nottingham, UK)/ $0.05 \%$ Tween-20 (Sigma-Aldrich) in PBS (5 minutes) and incubated with anti-calretinin (clone 5A5, Novocastra, Newcastle, UK), anti-cytokeratin 5/6 (clone D5/16B4, Zymed, San Francisco, CA), anti-carcinoembryonic antigen (clone A5B7, DAKO, Glostrup, Denmark), or antiTTF1 (clone EP1584Y, Abcam, Cambridge, UK) in $\mathrm{PBS} / 1 \%$ bovine serum albumin for 1 hour. Cells were washed twice in PBS and incubated with the appropriate fluorescein isothiocyanate-conjugated secondary antibody for 1 hour. After an additional PBS wash, cell nuclei were stained with $2 \mu \mathrm{g} / \mathrm{ml}$ Hoechst (Sigma-Aldrich) (5 minutes). Coverslips were mounted in Mowiol (Merck) and analyzed with a fluorescence microscope.

\section{RNA Isolation and Labeling}

Total RNA was isolated and treated with deoxyribonuclease I using the Ribonuclease-Free Deoxyribonuclease Set and the RNeasy Mini Kit according to the manufacturer's protocol (Qiagen, Courtaboeuf, France). RNA integrity was assessed using an Agilent 2100 bioanalyzer (Agilent Technologies, Massy, France). The Amino Allyl MessageAmp II aRNA Amplification Kit (Ambion, Courtaboeuf, France) was used to generate amino allyl RNA, which was subsequently labeled using the Cy3 PostLabeling Reactive Dye Pack (Amersham Biosciences, Piscataway, NJ). A reference sample, which consisted of a pool of equal quantities of amino allyl RNA from all biological samples, was Cy5-labeled.

\section{Microarrays}

Microarrays covering the entire genome were prepared in-house using 50-mer oligonucleotide probes obtained from the Ocimum human genome-wide microarray collection (Set A) (Ocimum Biosolutions B.V., IJsselstein, The Netherlands). Probes were diluted to a final concentration of $20 \mu \mathrm{mol} / \mathrm{L}$ in printing buffer (Buffer A from Ocimum Biosolutions) and printed onto epoxy-silane-coated glass slides (slide E-Schott-Nexterion; Schott, Clichy, France) using a Lucidea Arrayer (GE Health Care, Orsay, France). Before use, the chips were placed in blocking solution 1 (50 mmol/L ethanolamine [Sigma-Aldrich], 100 $\mathrm{mmol} / \mathrm{L}$ Tris base [pH 9, Sigma-Aldrich], 0.1\% SDS [BioRad, Marnes-la-Coquette, France]) for 15 minutes at $50^{\circ} \mathrm{C}$. They were rinsed twice in water and placed in washing solution $(4 \times$ standard saline citrate [SSC] [Invitrogen, Cergy Pontoise, France], 0.1\% SDS) for 15 minutes at $50^{\circ} \mathrm{C}$. They then were washed in water and dried by centrifugation. Finally, the chips were preincubated in blocking solution 2 ( $1 \%$ bovine serum albumin [SigmaAldrich], $3.5 \times$ SSC, $0.3 \%$ SDS) for 1 hour at $42^{\circ} \mathrm{C}$ and then washed five times in water (1 minute) and dried by centrifugation. All of these steps were performed to ensure the best fixation of labeled RNA samples to the chips. Each individual Cy3-labeled sample was mixed with an equal amount of Cy5-labeled reference sample (1 $\mu \mathrm{g}$ each), fragmented using the RNA Fragmentation Re- agents (Ambion), vacuum dried, and dissolved in $42-\mu$ l hybridization solution (5× Denhardt, $3.5 \times$ SSC, $0.3 \%$ SDS, $0.5 \mu \mathrm{g} / \mu \mathrm{l}$ yeast transfer RNA [Invitrogen], $0.5 \mu \mathrm{g} / \mu \mathrm{l}$ polyA RNA [Sigma-Aldrich], 50\% formamide, $\mathrm{H}_{2} \mathrm{O}$ ). Denaturation was achieved by heating at $98^{\circ} \mathrm{C}$ for 2 minutes and was followed immediately by a pre-annealing step at $37^{\circ} \mathrm{C}$ for 30 minutes. Subsequently, $40 \mu$ of each sample were pipetted onto the chips. Hybridization was performed at $42^{\circ} \mathrm{C}$ for 17 hours using a Glass Array Hybridization Cassette (Telechem, Sunnyvale, CA). Finally, the chips were washed in the following washing solutions ( $2 \times$ SSC, $0.1 \%$ SDS; $1 \times$ SSC; $0.2 \times$ SSC; $0.05 \times$ SSC) and dried by centrifugation. Microarray data are available in the Gene Expression Omnibus archive (accession GSE17310).

\section{Data Analysis and Statistics}

Hybridization and background signals, as well as quality control parameters, were measured with use of GenePix Pro 5.0 image analysis software (Molecular Devices, St-Grégoire, France). Technical biases were corrected by a Lowess normalization with use of a channel-bychannel procedure. ${ }^{17,18}$ For each microarray, Сy3 and Cy5 signal intensities were individually normalized to the median profile of all Cy3 or Cy5 signal intensities (values below background were filtered out). The expression level of each gene was calculated as $\log _{2}($ (Cy3/Cy5) so that relative variations, rather than absolute values, were used for interpretation. Gene expression profiles were used to classify genes and biological samples using a hierarchical clustering method with the Gene Cluster program (average linkage clustering using Pearson correlation coefficient as similarity metric). ${ }^{19}$ Results were displayed using the Java TreeView program (version 1.1.3 for Windows available at $h$ ttp://jtreeview.sourceforge.net). ${ }^{20}$ Validation of the most significant differences was carried out using a Student's $t$-test for unpaired samples. Multiple testing corrections were applied to reduce the number of false-positive results using the Benjamini and Hochberg False Discovery Rate. Genes were classified according to their adjusted $P$ value and their difference in relative expression (fold-change MPM vs ADCA).

\section{Real-time RT-PCR}

One microgram of total RNA was reverse-transcribed with use of Moloney-Murine Leukemia Virus Reverse Transcriptase (Invitrogen). PCR reactions were performed with use of QuantiTect Primers (Qiagen) and $\mathrm{RT}^{2}$ Real-Time SYBR-Green/ROX PCR Mastermix (tebu-bio, Le Perray-en-Yvelines, France), according to the manufacturer's instructions.

\section{Immunohistochemistry}

Immunohistochemistry was performed on paraffin-embedded tumor tissue samples with use of standard techniques. Primary antibody anti-type III collagen (Sigma-Aldrich) was used at a dilution of 1:100. A 
positive result was defined as the presence of cytoplasmic staining in tumor cells.

\section{Enzyme-Linked Immunosorbent Assays}

Pleural levels of MCP-1 and galectin-3 were determined using commercial enzyme-linked immunosorbent assay kits (Promokine, Heidelberg, Germany), according to the manufacturers' instructions, and results were expressed in $\mathrm{ng} / \mathrm{ml}$. Pleural samples were assayed in duplicate at a dilution of 1:10.

\section{Statistical Analysis}

All analyses, except for those from the microarray experiment, were performed with use of the Graphpad Prism software (Graphpad Software, La Jolla, CA). Data from the real-time RT-PCR experiments were compared with use of the non-parametric Mann-Whitney test. Data from enzyme-linked immunosorbent assays are reported as median and interquartile range. Comparisons between groups were performed with use of the Kruskal-Wallis test followed by Dunn's post test. Receiver-operator characteristic (ROC) curves were used to quantify marker performance and to provide estimates of sensitivity for a given specificity. Areas under ROC curves (AUC), reported with their 95\% confidence intervals, were calculated as an overall performance indicator of the biomarkers. The best statistical "cutoffs" were calculated by minimizing the distance between the point with specificity $=1$ and sensitivity $=1$ and the points on the ROC curves.

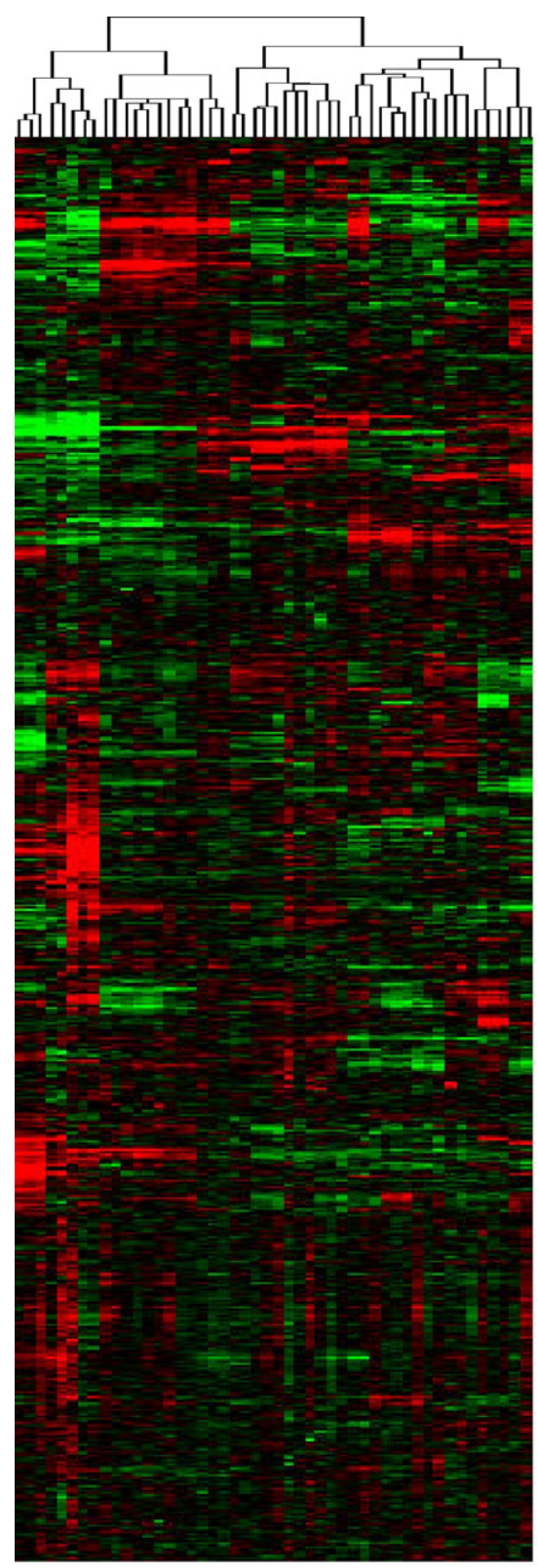

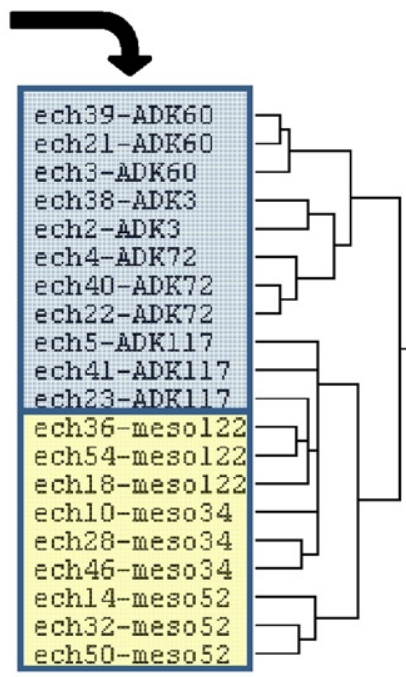

ADCA

ech27-meso 3 ech 45-meso 31 ech24-mesoll ech42-mesoll ech6-mesoll ech 25-mesol3 ech43-mesol3 ech7-mesol3 ch15-meso 5 ech 33-meso 56 ech51-meso 56 ech 26 -me 3030 ech 44-meso 30 ech8'-meso30 ech12-meso 37 ech30-meso 37 ech48-meso 3 ? echl3'-meso ech31-meso 47 ech 49-meso 4 ? echl6-mesog5 ech34-mesog 5 ech 52-mesog. echll-meso 36 ech 29 -meso36 ech 47-meso 36 ech35-mesog6 echl7-meso96 ech53-meso96
Figure 1. Hierarchical clustering of data from the microarray analysis of gene expression in tumor cell lines from patients with MPM and ADCA. The dendrogram representing the arrangement of samples is shown on the right Individual gene expression levels (in rows) fo each sample (in columns) were normalized and expressed relative to the median value for each gene in all samples. Genes expression ratios are represented as follows: red (high) $>$ black $>$ green (low). 


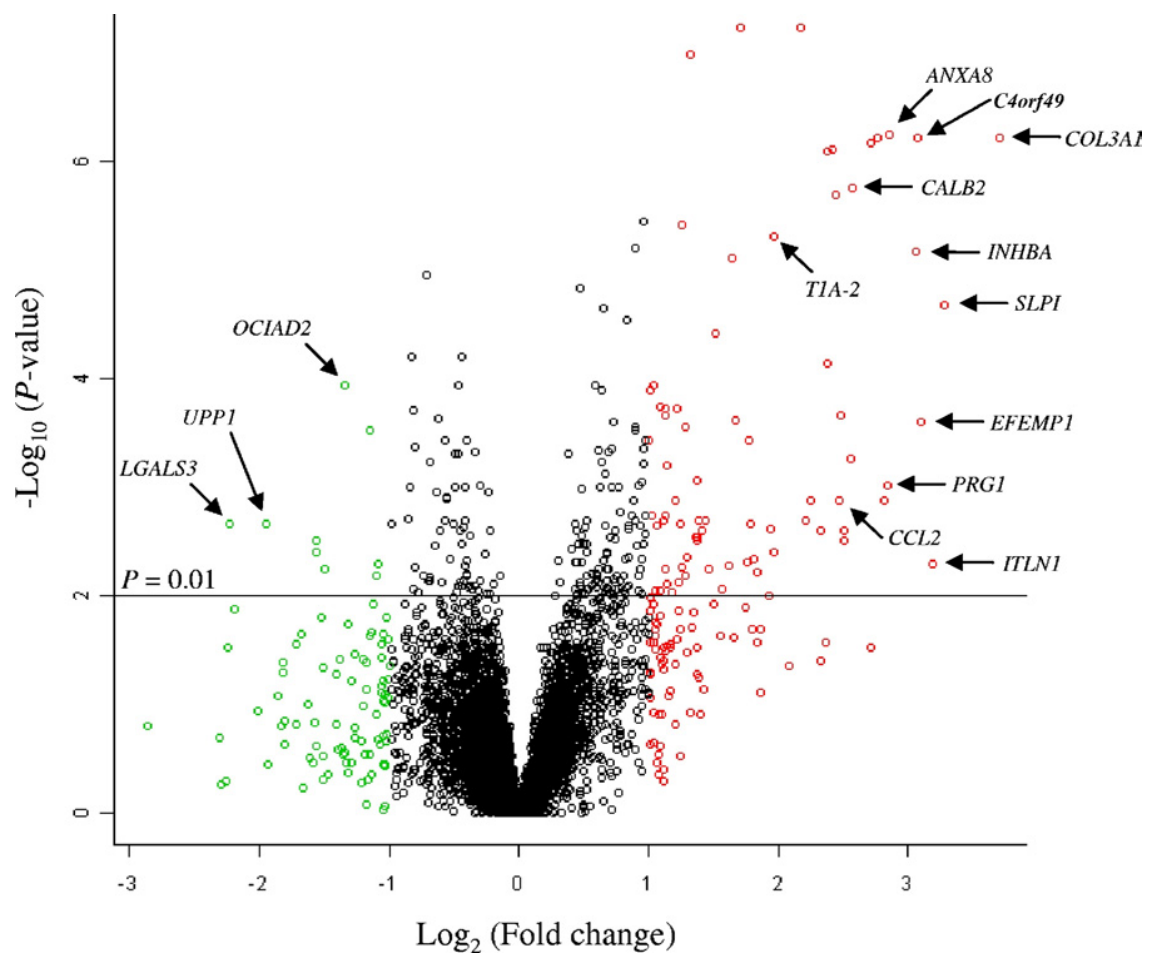

Figure 2. Volcano plot of microarray data showing differentially expressed genes plotted along dimensions of biological and statistical significance. Genes with the lowest corrected $P$ values are plotted at the top of the graph (eg, above the line corresponding to $P=0.01$ ) Genes overexpressed in mesothelioma or lung ADCA cells are shown in red or green, respectively (fold-change $>2$ ). Arrows indicate several genes of interest (not all) for which the expression has been validated using real-time RT-PCR.

\section{Results}

\section{Identification of Genes Differentially Expressed Between MPM and ADCA}

For the microarray experiment, we included a total of 51 samples, corresponding to biological replicates of 17 cancer cell lines. Because cell phenotype might evolve along with cell subculture, each cell line was included in the study at three different passages after thawing of the initial vials. Cells were used between the fifth and 25th passage. We examined the global gene expression profiles of these cell lines by performing a two-dimensional, unsupervised cluster analysis (Figure 1). The dendrogram, specifying the arrangement of samples, revealed that all MPM and lung ADCA samples grouped together. However, three MPM specimens (meso122, 34, 52) were on the same branch of the dendrogram as the ADCA specimens, highlighting the difficulty of distinguishing these pathologies, even with the use of microarrays.

To identify markers that could best distinguish lung ADCA from MPM, we kept genes represented on the microarrays with a high significant difference (adjusted $P<0.01$; fold-change $\geq 2$ ) with regard to the average expression levels between both tumor cell types. Under these conditions, we found 74 genes specifically overexpressed in MPM cell lines, whereas only nine were overexpressed in ADCA cell lines (Figure 2). A list of selected genes differentially expressed between ADCA and MPM cell lines, ranked according to their fold-change, is shown in Table 2. Among the genes overexpressed in mesothelioma cells, COL3A1, SLPI, and ITLN1 displayed the highest fold-change. CDH11, MYL9, ANXA8, COL3A1,
C40rf49, BDKRB1, UPK1B and CD200 displayed very low $P$ values $\left(\leq 10^{-7}\right)$, indicating that there might be only a weak overlap between MPM and ADCA samples for these genes. On the contrary, the genes that were most significantly overexpressed in ADCA cells, such as LGALS3 or OCIAD2, displayed relatively higher $P$ values.

\section{Validation of Microarray Data}

We used real-time RT-PCR to confirm the expression levels of selected genes by comparing cDNA generated from total RNA from each cell line used in the microarray (pool of each triplicate), as well as cDNA from two other lung cancer cell lines (A549 and H69) (Figure 3). As expected, we found that RT-PCR results reflected those obtained with microarrays, but most of the time with a higher fold-change, especially when genes were barely detectable (ct $>35)$. We confirmed that COL3A1, SLPI, ITLN1, and several other genes shown in Table 2 are overexpressed in MPM cells (compared with lung cancer cells), while OCIAD2, UPP1, and LGALS3 transcripts are more abundant in lung cancer cells.

\section{Validation of COL3A1 as a Suitable Marker for Immunohistochemistry}

Our microarray experiment led to the identification of COL3A1 as being overexpressed in mesothelioma cells compared with lung ADCA cells, with the highest foldchange and a low $P$ value $\left(5.97 \times 10^{-7}\right)$. This gene encodes pro-alpha1 chains of type III collagen, which 
Table 2. Selected Genes Differentially Expressed Between Mesothelioma and Lung ADCA

\begin{tabular}{|c|c|c|c|c|}
\hline Description & Name & Accession no. & Fold-change & Adjusted $P$ value \\
\hline Collagen, type III, alpha 1 & COL3A1 & NM_000090.2 & 13.002 & 5.97E-07 \\
\hline Secretory leukocyte peptidase inhibitor & SLPI & NM_003064.2 & 9.654 & 2.09E-05 \\
\hline Intelectin 1 (galactofuranose binding) & ITLN1 & NM_017625.2 & 9.132 & 5.05E-03 \\
\hline $\begin{array}{l}\text { EGF-containing fibulin-like extracellular matrix } \\
\text { protein } 1\end{array}$ & EFEMP1 & NM_004105.2 & 8.563 & $2.48 \mathrm{E}-04$ \\
\hline Chromosome 4 open reading frame 49 & C4orf49 & NM_032623.2 & 8.378 & $6.05 \mathrm{E}-07$ \\
\hline $\begin{array}{l}\text { Inhibin, beta } A \text { (activin } A \text {, activin AB alpha } \\
\text { polypeptide) }\end{array}$ & INHBA & NM_002192.2 & 8.346 & $6.75 \mathrm{E}-06$ \\
\hline Annexin A8 & ANXA8 & NM_001630.1 & 7.208 & 5.64E-07 \\
\hline Serglycin & SRGN & NM_002727.2 & 7.057 & 1.29E-03 \\
\hline Bradykinin receptor B1 & $B D K R B 1$ & NC_000014.8 & 6.529 & $6.59 \mathrm{E}-07$ \\
\hline Calbindin 2, 29kDa (calretinin) & CALB2 & BC015484.2 & 5.932 & 1.73E-06 \\
\hline $\begin{array}{l}\text { Retinoic acid receptor responder (tazarotene } \\
\text { induced) } 1\end{array}$ & RARRES1 & BC029640.1 & 5.871 & 5.32E-04 \\
\hline Serum amyloid $A 1$ & SAA1 & BC105796.1 & 5.701 & $2.45 \mathrm{E}-03$ \\
\hline Transgelin & TAGLN & BT019649.1 & 5.657 & 3.04E-03 \\
\hline Crystallin, alpha B & CRYAB & NM_001885.1 & 5.583 & $2.15 \mathrm{E}-04$ \\
\hline Chemokine (C-C motif) ligand 2 & CCL2 & NM_002982.3 & 5.541 & $1.29 \mathrm{E}-03$ \\
\hline Caldesmon 1 & CALD1 & BC040354.1 & 5.450 & 2.00E-06 \\
\hline Uroplakin 1B & UPK1B & BC063568.1 & 5.342 & 7.68E-07 \\
\hline CD200 antigen & CD200 & AY603771.1 & 5.189 & 8.08E-07 \\
\hline Chromosome 8 open reading frame 84 & C8orf84 & NM_153225.2 & 5.182 & 7.29E-05 \\
\hline $\begin{array}{l}\text { Secreted protein, acidic, cysteine-rich } \\
\text { (osteonectin) }\end{array}$ & SPARC & NM_003118.2 & 5.010 & $2.45 \mathrm{E}-03$ \\
\hline Latexin & $L X N$ & NM_020169.2 & 4.743 & 1.33E-03 \\
\hline Tropomyosin 2 (beta) & TPM2 & AL133410.32 & 4.608 & 1.99E-03 \\
\hline Cadherin 11 , type 2 , OB-cadherin (osteoblast) & $\mathrm{CDH11}$ & NM_001797.2 & 4.487 & 5.87E-08 \\
\hline Neuromedin $U$ & NMU & NM_006681.1 & 3.912 & 3.96E-03 \\
\hline Podoplanin & $P D P N$ & AL359771.27 & 3.894 & 4.89E-06 \\
\hline Prostaglandin I2 (prostacyclin) synthase & PTGIS & NM_000961.3 & 2.396 & $3.75 \mathrm{E}-06$ \\
\hline OCIA domain containing 2 & OCIAD2 & CR7449310.1 & 0.394 & 1.14E-04 \\
\hline Chromatin modifying protein $4 \mathrm{C}$ & CHMP4C & NM_152284.3 & 0.355 & $5.71 \mathrm{E}-03$ \\
\hline ERBB receptor feedback inhibitor 1 & $E R R F / 1$ & NM_018948.2 & 0.339 & $3.91 \mathrm{E}-03$ \\
\hline Uridine phosphorylase 1 & UPP1 & BC001405.1 & 0.259 & 2.18E-03 \\
\hline Lectin, galactoside-binding, soluble, 3 (galectin 3) & LGALS3 & BC068068.1 & 0.213 & 2.14E-03 \\
\hline
\end{tabular}

The genes shown in the table are ranked according to their fold-change (MPM vs ADCA). $P$ values were obtained using a two-tailed Student's $t$-test for unpaired samples and adjusted according the Benjamini and Hochberg procedure.

is a fibrillar collagen usually found in extensible connective tissues. Immunohistochemistry for COL3A1, performed on an independent panel of 11 tumor biopsies (5 MPM and 6 ADCA), showed a granular, cytoplasmic staining in $100 \%$ of mesothelioma cells (Figure 4). This staining was noted as weak/moderate $(+)$ and moderate/strong $(++)$ in $60 \%$ and $40 \%$ of mesothelioma cells, respectively. Conversely, no staining of ADCA cells was observed in the lung tumors examined (only the stromal compartment was immunostained).

\section{Assessment of the Usefulness of CCL2 and Galectin-3 in Pleural Fluids}

Of the genes identified in this study, several encode soluble markers that may be released into the pleural fluids. We chose to analyze the levels of $\mathrm{C}-\mathrm{C}$ motif chemokine 2 (CCL2) and galectin-3. CCL2 is a chemokine with potent immunoinhibitory effects that recently has been proposed as a valuable target for immunotherapy. ${ }^{21,22}$ Galectin-3, encoded by LGALS3, is a multifunctional protein that has been implicated in tumor invasion and metastasis. ${ }^{23}$ The levels of these two proteins were assessed in an independent set of pleural fluids (Table 1). We found that the CCL2 concentration was significantly higher in patients with mesothelioma $(n=61)$ than in subjects with ADCA $(n=25)$ or BPEs $(n=15)$ (Figure 5A): median (interquartile range) $=$ $2.99 \mathrm{ng} / \mathrm{ml}$ (1.76 to 6.01$)$ vs $0.99 \mathrm{ng} / \mathrm{ml}(0.51$ to 1.83$)$ or $1.47 \mathrm{ng} / \mathrm{ml}$ (0.80 to 1.56$)$, respectively, $P<0.0001$. Conversely, the galectin-3 concentration was lower in mesothelioma than in ADCAs: $11.50 \mathrm{ng} / \mathrm{ml}$ (6.73 to 23.53) vs $24.74 \mathrm{ng} / \mathrm{ml}$ (20.42 to 70.35), $P<0.0001$ (Figure 5B). However, galectin-3 may not be useful to distinguish MPM from BPE (17.64 ng/ml (14.81 to 24.68)). ROC analysis of CCL2 and galectin-3 showed an AUC of 0.8030 (95\% confidence interval: 0.7061 to $0.8998)$ and 0.7980 (0.7019 to 0.8942) for differentiating MPM and ADCA (Figure 5C), with best statistical cut-offs of $1.79 \mathrm{ng} / \mathrm{ml}$ (sensitivity $=76 \%$, specificity $=$ $73.8 \%$ ) and $19.97 \mathrm{ng} / \mathrm{ml}$ (sensitivity $=80.0 \%$, specificity $=$ $73.8 \%$ ), respectively. The AUC of CCL2 for MPM vs BPE was 0.7716 (0.6429 to 0.9003) for CCL2 (Figure 5D).

\section{Discussion}

Despite recent improvements, the diagnosis and treatment of MPM is still a major challenge. Because of the unspecific symptoms and tissue polymorphism of this cancer, MPM can be confused with benign pleural dis- 

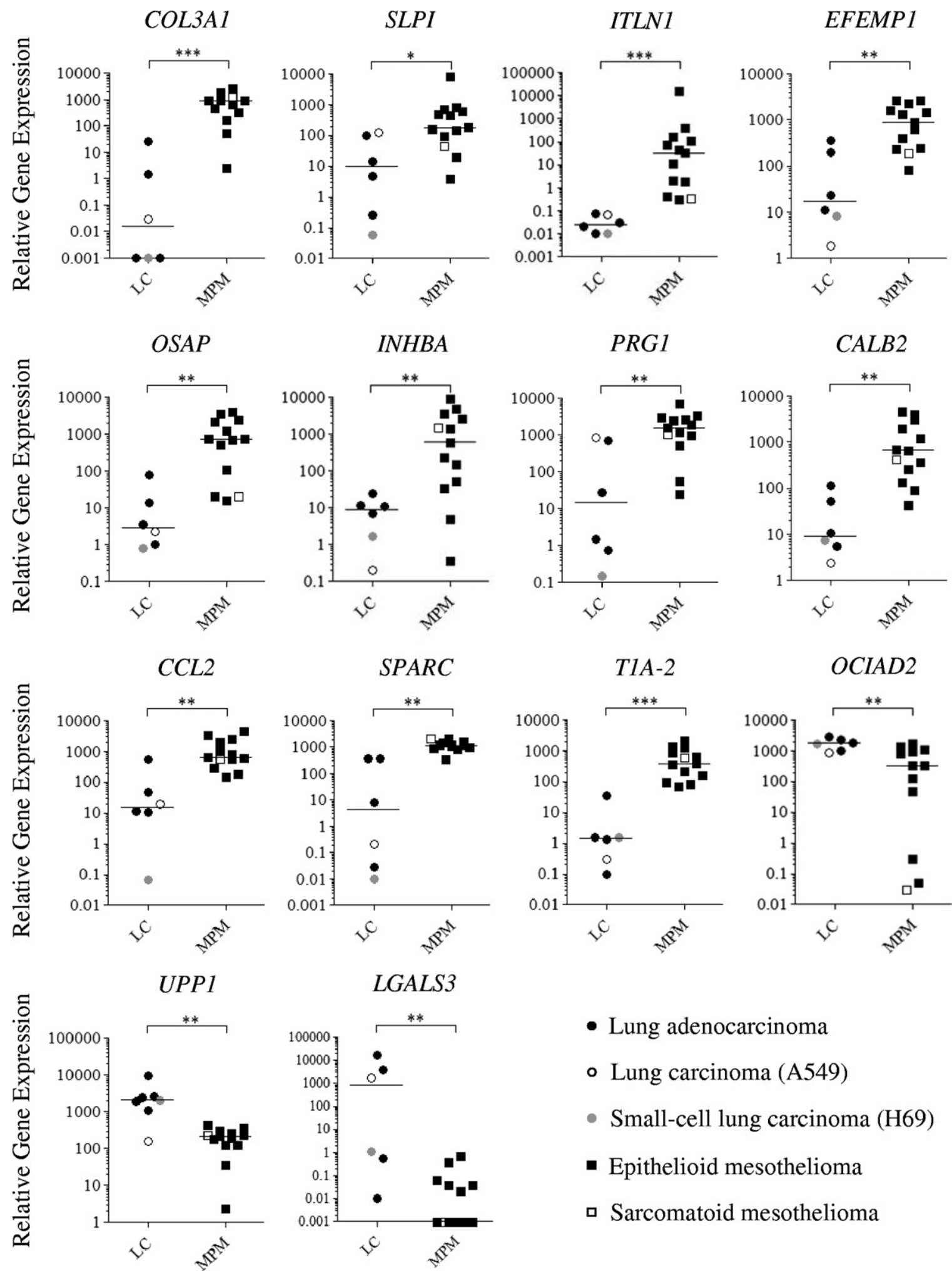

LGALS3

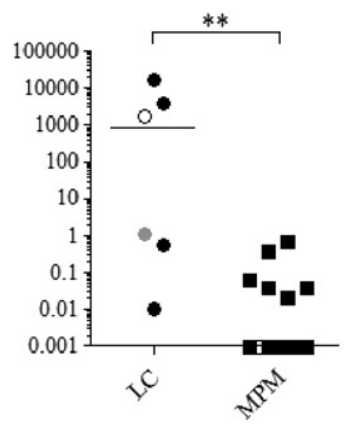

- Lung adenocarcinoma

- Lung carcinoma (A549)

- Small-cell lung carcinoma (H69)

- Epithelioid mesothelioma

- Sarcomatoid mesothelioma

Figure 3. Validation of microarray data. Real-time RT-PCR was performed for selected genes in mesothelioma (MPM) and lung cancer (LC) cells. Individual mRNA levels were normalized to RPLPO (ribosomal phosphoprotein PO housekeeping gene), and statistical analyses were performed using the Mann-Whitney test (black bars represent the median values). ${ }^{*} P<0.05 ;{ }^{* *} P<0.01 ;{ }^{* * * *} P<0.001$

eases or with pleural metastasis of ADCAs. Indeed, the performance of diagnostic markers in identifying mesothelioma cancer cells is still questionable. Various immunohistochemical markers are currently available. ${ }^{4}$ How- ever, their value in the correct identification of MPM cases using biopsy samples (or cells present in pleural effusions) is, to some extent, limited by nonspecific staining, focal staining, or poor staining quality. More re- 

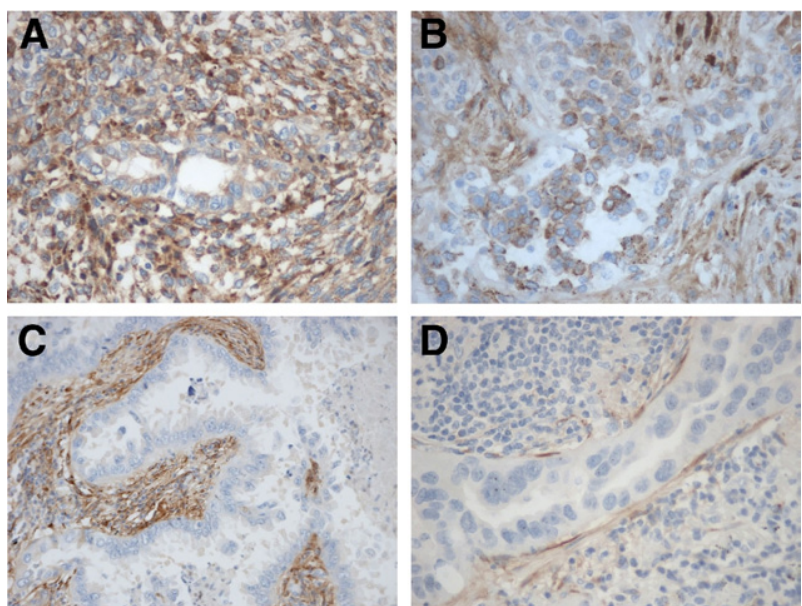

Figure 4. Immunohistochemical staining of tumor tissues from four patient with mesothelioma [magnification: $\times 200$ (A and B)] or lung ADCA [magnification: $\times 200(\mathbf{C}) ; \times 400(\mathbf{D})$ ], using antibodies specific for COL3A1. Cytoplasmic staining can be detected in mesothelioma cells but not in lung ADCA cells. Note also the positive staining of the stroma $(\mathbf{C})$.

cently, promising soluble markers, such as mesothelin and osteopontin, have been proposed, but their clinical utilities are still under investigation. ${ }^{24}$ Because an accurate diagnosis is crucial, both for the management of patients with MPM and also for the settlement of financial compensation for individuals with a history of asbestos exposure, the development of new tools and the improvement of existing diagnostic procedures are of major interest.

Because the presence of a pleural (unilateral) effusion indicates MPM in the majority of patients, we evaluated the possibility of using malignant cells from pleural fluids in a genome-wide analysis with the goal of identifying novel and specific markers to facilitate an easier identification of MPM. Most of the microarray studies reported to date have been performed using tumor biopsy specimens, but such profiling can be compromised by contamination with different cell types. Furthermore, some authors have reported difficulties in performing gene expression studies on cells contained in pleural fluids, essentially because of RNA "weakness" of their samples. ${ }^{25}$ In our study, we used tumor cell lines isolated from pleural effusions of patients with MPM or ADCA and characterized for the expression of a panel of diagnostic markers. Gene expression profiling of a panel of 17 cell lines revealed a good segregation between samples, in agreement with the initial classification made by immunohistochemical staining of corresponding pleural biopsy specimens. Based on both statistical and biological criteria, we identified 83 genes differentially expressed between MPM and lung ADCA. It is interesting that calretinin (encoded by CALB2) and podoplanin (encoded by PDPN), two validated immunohistochemical markers for MPM diagnosis, also were identified in our study as being overexpressed in mesothelioma compared with ADCA cells, strengthening our results. Furthermore, several genes previously identified (after profiling tumor biopsy specimens) and described to be useful in a PCR-based assay also were found to be discriminatory in our study
(EFEMP1, ANXA8, CALB2, CD200, and PTG/S). ${ }^{10,26}$ Interestingly, our microarray investigation, validated by realtime quantitative RT-PCR, led to the identification of novel genes preferentially expressed in MPM (eg, COL3A1, SLPI, ITLN1, and CCL2). Conversely, we noted that OCIAD2, UPP1, and LGALS3 are poorly expressed by mesothelioma cells.

The clinical signs of MPM are usually nonspecific and should not be used alone as diagnostic criteria, even in the case of previous asbestos exposure. It is recommended that the diagnosis of MPM should always be based on immunohistochemical evaluation. ${ }^{27}$ To discriminate MPM from ADCA, it is recommended that two markers with positive diagnostic value and two markers with negative diagnostic value be used. In the present study, COL3A1 was shown to be a novel, interesting positive marker for MPM, potentially useful in immunohistochemistry. Indeed, we showed that anti-COL3A1 antibody stained mesothelioma but not lung ADCA cells in the 11 tumors analyzed. Of interest, in one case of mixed subtype mesothelioma, both epithelial and sarcomatoid cells were found to be positive for COL3A1. These results are encouraging and should be confirmed in a larger number of samples, including other tumor types and atypical mesothelial hyperplasia.

During the past few years, several attempts have been made to identify soluble molecules that can aid in the
A

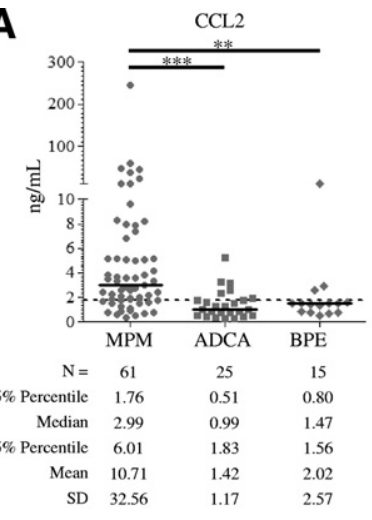

C

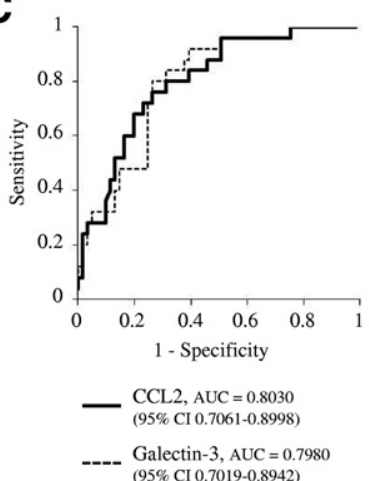

B

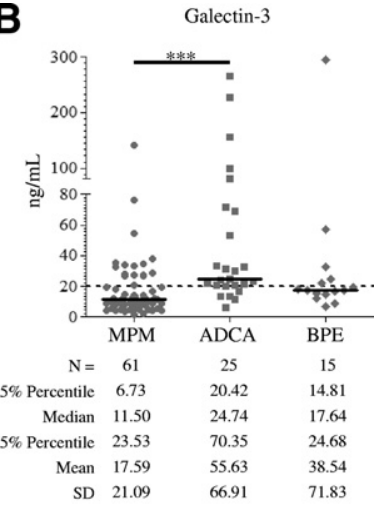

D

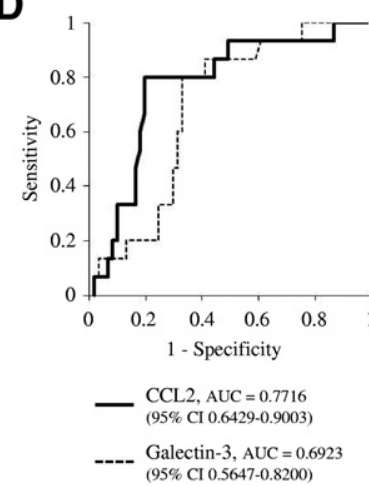

Figure 5. CCL2 and galectin-3 levels in pleural effusions from patients with mesothelioma (MPM), metastatic adenocarcinoma (ADCA), or in benign pleural effusions (BPE) (A and B). Horizontal bars are median values. Dashed lines represent proposed cut-off values. Statistical significance was calculated using the Kruskal-Wallis test followed by Dunn's post-test $(\mathbf{B}){ }^{* * *} P<0.01$, $\left.{ }^{*} * * * P<0.001\right)$. ROC curves for CCL2 and galectin-3 in differentiating MPM and ADCA (C) or MPM and BPE (D). 
early diagnosis of MPM with the use of serum and pleural effusion samples. Recent reports have shed light on the utility of two possible markers, soluble mesothelin (or SMRP) and osteopontin. ${ }^{6-8,28,29}$ Mesothelin is expressed on the surface of normal mesothelial cells and is overexpressed in various cancers, including MPM, ovarian carcinoma, and lung carcinoma. ${ }^{30,31}$ Our group has recently shown that the release of soluble mesothelin (SMRP) into the pleural fluids and blood of patients may result from both aberrant splicing and protease cleavage by matrix metalloproteinases and/or a disintegrin and metalloproteinases. ${ }^{32}$ However, SMRP levels are low in non-epithelioid MPM, and its poor sensitivity limits the value of SMRP as a unique marker. ${ }^{7,9}$ Combining SMRP with other potential markers has been suggested, but no combination with other known markers (eg, hyaluronic acid, CA125, and osteopontin) has been proven useful for improving SMRP value in MPM diagnosis. ${ }^{9,33,34}$ In the present work we also focused our attention on genes encoding soluble/secreted proteins, the expression of which could help to distinguish MPM from other pleural diseases. Our attention was retained by CCL2, also known as monocyte chemoattractant protein 1, because this chemokine with pro-tumorigenic and immunomodulatory effects could also be used as a therapeutic target. ${ }^{35-39}$ In fact, it was shown recently that overexpression of CCL2 by tumor cells injected into the pleural cavity of immunocompetent mice led to increased malignant pleural effusion volumes and reduced survival. ${ }^{40}$ Furthermore, CCL2 blockade reduced tumor growth and increased $\mathrm{CD}^{+}$T-cell response in mouse models. ${ }^{21,41}$ Here we have shown that CCL2 levels are significantly higher in pleural effusions of patients with MPM (including sarcomatoid and mixed subtypes) than in patients with metastatic cancer (not only of lung origin) and patients with benign pleural effusions. The ROC curve analysis of CCL2 for differentiating MPM from ADCA indicated an AUC of 0.8030 , a slightly better result than the AUC values reported for SMRP in other studies $\left(0.758,0.793\right.$, and 0.796) ${ }^{7,9,42}$ We determined that, using the best "theoretical" cut-off value of $1.79 \mathrm{ng} / \mathrm{ml}$, the sensitivity and specificity of CCL2 were $76 \%$ and $73.8 \%$, respectively. However, to reach a sensitivity of $96 \%$ (with a cut-off of $3.26 \mathrm{ng} / \mathrm{ml}$ ), the specificity fell to $49.2 \%$, but this value was still higher than the test performances of other established tumor markers, such as the prostate-specific antigen currently used for prostate cancer diagnosis. ${ }^{43}$ The ROC curve analysis of CCL2 for differentiating MPM from BPE shows an AUC of 0.7716 , an encouraging result despite the relatively small number of benign cases included in this study $(n=15)$.

Our work also indicated that galectin-3 could be used as a negative marker to exclude a diagnosis of MPM. Our microarray data indicate that $L G A L S 3$ is overexpressed in lung ADCA cells with the highest fold-change. Here we have shown that galectin-3 levels are significantly higher in pleural effusions of patients with ADCA than in patients with MPM. The ROC curve analysis of galectin-3 shows an AUC of 0.7980 , which is similar to those of CCL2. Of interest, in thyroid cells, it has been shown that nuclear galectin-3 can interact with thyroid transcription factor 1 and can up-regulate its transcriptional activity. ${ }^{44} \mathrm{Be}-$ cause thyroid transcription factor 1 is used in immunohistochemistry as a positive marker of lung cancer, we compared galectin-3 levels in pleural fluids of patients with MPM $(n=61)$ and patients with lung cancer $(n=20$, including patients from another hospital). We found that galectin-3 levels in patients with lung cancer were even higher than in the other cancers: median (interquartile range) $=37.17 \mathrm{ng} / \mathrm{ml}$ (22.08 to 79.47). The AUC was also higher $(0.8721,95 \%$ confidence interval $=0.7961$ to 0.9442 ), indicating that galectin-3 may be a very good marker for lung ADCA. In this case, the best cut-off value $(15.24 \mathrm{ng} / \mathrm{ml})$ gives $100 \%$ sensitivity and $67.21 \%$ specificity.

In conclusion, this study suggests novel, putative markers that may facilitate the diagnosis of MPM. Although all potential candidate genes have not yet been tested, we have shown that type III collagen, CCL2, and galectin-3 may be useful, either for immunohistochemical analyses of tumor tissues or for the assessment of soluble factors in pleural effusions. The data presented here are promising but warrant further multicenter investigations with larger series of patients. In addition, the diagnostic and prognostic value of serum (or urinary) CCL2 and galectin-3 levels should be evaluated.

\section{Acknowledgments}

We thank Dr. Remi Houlgatte and Catherine Chevalier (Plateforme Puces à ADN de Nantes) for their help and expertise in setting up the microarray experiment and Raluca Teusan, Audrey Bihouée, and Edouard Hirchaud for bioinformatic interpretation and analysis. We also thank Dr. Jean-François Fonteneau for his critical reading of this manuscript.

\section{References}

1. Hodgson JT, Darnton A: The quantitative risks of mesothelioma and lung cancer in relation to asbestos exposure. Ann Occup Hyg 2000, 44:565-601

2. Robinson BW, Musk AW, Lake RA: Malignant mesothelioma. Lancet 2005, 366:397-408

3. Beasley MB: Immunohistochemistry of pulmonary and pleural neoplasia. Arch Pathol Lab Med 2008, 132:1062-1072

4. Ordonez NG: What are the current best immunohistochemical markers for the diagnosis of epithelioid mesothelioma? A review and update. Hum Pathol 2007, 38:1-16

5. Creaney J, Yeoman D, Demelker Y, Segal A, Musk AW, Skates SJ Robinson BW: Comparison of osteopontin, megakaryocyte potentiating factor, and mesothelin proteins as markers in the serum of patients with malignant mesothelioma. J Thorac Oncol 2008, 3:851-857

6. Pass HI, Wali A, Tang N, Ivanova A, Ivanov S, Harbut M, Carbone M, Allard J: Soluble mesothelin-related peptide level elevation in mesothelioma serum and pleural effusions. Ann Thorac Surg 2008, 85:265272

7. Scherpereel A, Grigoriu B, Conti M, Gey T, Gregoire M, Copin MC, Devos P, Chahine B, Porte H, Lassalle P: Soluble mesothelin-related peptides in the diagnosis of malignant pleural mesothelioma. Am J Respir Crit Care Med 2006, 173:1155-1160

8. Scherpereel A, Lee YC: Biomarkers for mesothelioma. Curr Opin Pulm Med 2007, 13:339-443

9. Grigoriu BD, Scherpereel A, Devos P, Chahine B, Letourneux M, Lebailly P, Gregoire M, Porte H, Copin MC, Lassalle P: Utility of osteopontin and serum mesothelin in malignant pleural mesothelioma 
diagnosis and prognosis assessment. Clin Cancer Res 2007, 13:2928-2935

10. Gordon GJ, Jensen RV, Hsiao LL, Gullans SR, Blumenstock JE, Ramaswamy S, Richards WG, Sugarbaker DJ, Bueno R: Translation of microarray data into clinically relevant cancer diagnostic tests using gene expression ratios in lung cancer and mesothelioma. Cancer Res 2002, 62:4963-4967

11. Gordon GJ, Jensen RV, Hsiao LL, Gullans SR, Blumenstock JE, Richards WG, Jaklitsch MT, Sugarbaker DJ, Bueno R: Using gene expression ratios to predict outcome among patients with mesothelioma. J Natl Cancer Inst 2003, 95:598-605

12. Gordon GJ, Rockwell GN, Godfrey PA, Jensen RV, Glickman JN, Yeap BY, Richards WG, Sugarbaker DJ, Bueno R: Validation of genomics-based prognostic tests in malignant pleural mesothelioma. Clin Cancer Res 2005, 11:4406-4414

13. Gordon GJ, Rockwell GN, Jensen RV, Rheinwald JG, Glickman JN, Aronson JP, Pottorf BJ, Nitz MD, Richards WG, Sugarbaker DJ, Bueno R: Identification of novel candidate oncogenes and tumor suppressors in malignant pleural mesothelioma using large-scale transcriptional profiling. Am J Pathol 2005, 166:1827-1840

14. Mohr S, Keith G, Galateau-Salle F, Icard P, Rihn BH: Cell protection, resistance and invasiveness of two malignant mesotheliomas as assessed by 10K-microarray. Biochim Biophys Acta 2004, 1688:43-60

15. Pass HI, Liu Z, Wali A, Bueno R, Land S, Lott D, Siddiq F, Lonardo F, Carbone M, Draghici S: Gene expression profiles predict survival and progression of pleural mesothelioma. Clin Cancer Res 2004, 10:849859

16. Mohr S, Bottin MC, Lannes B, Neuville A, Bellocq JP, Keith G, Rihn $\mathrm{BH}$ : Microdissection, mRNA amplification and microarray: a study of pleural mesothelial and malignant mesothelioma cells. Biochimie 2004, 86:13-19

17. Workman C, Jensen LJ, Jarmer H, Berka R, Gautier L, Nielser HB, Saxild HH, Nielsen C, Brunak S, Knudsen S: A new non-linear normalization method for reducing variability in DNA microarray experiments. Genome Biol 2002, 3(9):research0048 [Epub 2002 Aug 30]

18. Yang YH, Dudoit S, Luu P, Lin DM, Peng V, Ngai J, Speed TP: Normalization for cDNA microarray data: a robust composite method addressing single and multiple slide systematic variation. Nucleic Acids Res 2002, 30:e15

19. Eisen MB, Spellman PT, Brown PO, Botstein D: Cluster analysis and display of genome-wide expression patterns. Proc Natl Acad Sci USA 1998, 95:14863-14868

20. Saldanha AJ. Java treeview: extensible visualization of microarray data. Bioinformatics. 2004, 20:3246-3248. Epub doi:10.1093/bioinformatics/bth349

21. Conti I, Rollins BJ: CCL2 (monocyte chemoattractant protein-1) and cancer. Semin Cancer Biol 2004, 14:149-154

22. Fridlender ZG, Buchlis G, Kapoor V, Cheng G, Sun J, Singhal S, Crisanti MC, Wang LC, Heitjan D, Snyder LA, Albelda SM: CCL2 blockade augments cancer immunotherapy. Cancer Res 2010, 70:109-118

23. Califice S, Castronovo V, Van Den Brule F: Galectin-3 and cancer (Review). Int J Oncol 2004, 25:983-992

24. Grigoriu BD, Grigoriu C, Chahine B, Gey T, Scherpereel A: Clinical utility of diagnostic markers for malignant pleural mesothelioma. Monaldi Arch Chest Dis 2009, 71:31-38

25. Greillier L, Roll P, Barlesi F, Robaglia-Schlupp A, Fraticelli A, Cau P, Astoul P: [Role of DNA microarrays in the diagnosis of pleural exudates: a feasibility study]. Rev Mal Respir 2007, 24:859-867

26. Holloway AJ, Diyagama DS, Opeskin K, Creaney J, Robinson BW, Lake RA, Bowtell DD: A molecular diagnostic test for distinguishing lung adenocarcinoma from malignant mesothelioma using cells collected from pleural effusions. Clin Cancer Res 2006, 12:5129-5135

27. Scherpereel A, Astoul $P$, Baas $P$, Berghmans $T$, Clayson $H$, de Vuyst $P$, Dienemann $H$, Galateau-Salle F, Hennequin C, Hillerdal G, Le Pechoux C, Mutti L, Pairon JC, Stahel R, van Houtte P, van Meerbeeck J, Waller D, Weder W: Guidelines of the European Respiratory Society and the European Society of Thoracic Surgeons for the management of malignant pleural mesothelioma. Eur Respir J 2010, 35: 479-495
28. Hassan R, Remaley AT, Sampson ML, Zhang J, Cox DD, Pingpank J, Alexander R, Willingham M, Pastan I, Onda M: Detection and quantitation of serum mesothelin, a tumor marker for patients with mesothelioma and ovarian cancer. Clin Cancer Res 2006, 12:447-453

29. Pass HI, Lott D, Lonardo F, Harbut M, Liu Z, Tang N, Carbone M, Webb C, Wali A: Asbestos exposure, pleural mesothelioma, and serum osteopontin levels. N Engl J Med 2005, 353:1564-1573

30. Chang K, Pastan I: Molecular cloning of mesothelin, a differentiation antigen present on mesothelium, mesotheliomas, and ovarian cancers. Proc Natl Acad Sci USA 1996, 93:136-140

31. Scholler N, Fu N, Yang Y, Ye Z, Goodman GE, Hellstrom KE, Hellstrom I: Soluble member(s) of the mesothelin/megakaryocyte potentiating factor family are detectable in sera from patients with ovarian carcinoma. Proc Natl Acad Sci USA 1999, 96:11531-11536

32. Sapede C, Gauvrit A, Barbieux I, Padieu M, Cellerin L, Sagan C, Scherpereel A, Dabouis G, Gregoire M: Aberrant splicing and protease involvement in mesothelin release from epithelioid mesothelioma cells. Cancer Sci 2008, 99:590-594

33. Creaney J, van Bruggen I, Hof M, Segal A, Musk AW, de Klerk N, Horick N, Skates SJ, Robinson BW: Combined CA125 and mesothelin levels for the diagnosis of malignant mesothelioma. Chest 2007, 132:1239-1246

34. Grigoriu B, Chahine B, Zerimech F, Gregoire M, Balduyck M, Copin MC, Devos P, Lassalle P, Scherpereel A: Serum mesothelin has a higher diagnostic utility than Hyaluronic acid in malignant mesothelioma. Clin Biochem 2009, 42:1046-1050

35. Hembruff SL, Jokar I, Yang L, Cheng N: Loss of transforming growth factor-beta signaling in mammary fibroblasts enhances CCL2 secretion to promote mammary tumor progression through macrophagedependent and -independent mechanisms. Neoplasia 2010, 12:425433

36. Roca $\mathrm{H}$, Varsos ZS, Pienta $\mathrm{KJ}$ : CCL2 is a negative regulator of AMP-activated protein kinase to sustain mTOR complex-1 activation, survivin expression, and cell survival in human prostate cancer PC3 cells. Neoplasia 2009, 11:1309-1317

37. Vitiello PF, Shainheit MG, Allison EM, Adler EP, Kurt RA: Impact of tumor-derived CCL2 on T cell effector function. Immunol Lett 2004, 91:239-245

38. Zhang J, Lu Y, Pienta KJ: Multiple roles of chemokine (C-C motif) ligand 2 in promoting prostate cancer growth. J Natl Cancer Inst 2010, 102:522-528

39. Zhang J, Patel L, Pienta KJ: CC chemokine ligand 2 (CCL2) promotes prostate cancer tumorigenesis and metastasis. Cytokine Growth Factor Rev 2010, 21:41-48

40. Stathopoulos GT, Psallidas I, Moustaki A, Moschos C, Kollintza A, Karabela S, Porfyridis I, Vassiliou S, Karatza M, Zhou Z, Joo M, Blackwell TS, Roussos C, Graf D, Kalomenidis I: A central role for tumor-derived monocyte chemoattractant protein-1 in malignant pleural effusion. J Natl Cancer Inst 2008, 100:1464-1476

41. Fridlender ZG, Kapoor V, Buchlis G, Cheng G, Sun J, Wang LC, Singhal S, Snyder LA, Albelda SM: CCL2 blockade inhibits lung cancer tumor growth by altering macrophage phenotype and activating CD8+ cells. Am J Respir Cell Mol Biol 2010 doi:10.1165/ rcmb.2010-00800C

42. Creaney J, Yeoman D, Naumoff LK, Hof M, Segal A, Musk AW, De Klerk N, Horick N, Skates SJ, Robinson BW: Soluble mesothelin in effusions: a useful tool for the diagnosis of malignant mesothelioma. Thorax 2007, 62:569-576

43. Sokoll LJ, Sanda MG, Feng Z, Kagan J, Mizrahi IA, Broyles DL, Partin AW, Srivastava S, Thompson IM, Wei JT, Zhang Z, Chan DW: A prospective, multicenter, National Cancer Institute Early Detection Research Network study of [-2]proPSA: improving prostate cancer detection and correlating with cancer aggressiveness. Cancer Epidemiol Biomarkers Prev 2010, 19:1193-1200

44. Paron I, Scaloni A, Pines A, Bachi A, Liu FT, Puppin C, Pandolfi M, Ledda L, Di Loreto C, Damante G, Tell G: Nuclear localization of Galectin-3 in transformed thyroid cells: a role in transcriptional regulation. Biochem Biophys Res Commun 2003, 302:545-553 